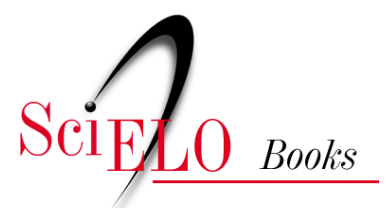

\title{
5 - Patrimônio cultural imaterial indígena: os tapuia paiacu do município de Apodi/RN
}

\author{
Joelma Pinto de Sousa
}

\section{SciELO Books / SciELO Livros / SciELO Libros}

SOUSA, J. P. Patrimônio cultural imaterial indígena: os tapuia paiacu do município de Apodi/RN. In: OLIVEIRA, G. M. C., and VIEIRA, K. M. A., eds. Patrimônio, povos do campo e memórias: diálogos com a cultura, a arte e a educação [online]. Mossoró: EdUFERSA, 2020, pp. 81-92. ISBN: 978-65-8710809-4. https://doi.org/10.7476/9786587108605.0006.

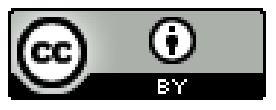

All the contents of this work, except where otherwise noted, is licensed under a Creative Commons Attribution 4.0 International license.

Todo o conteúdo deste trabalho, exceto quando houver ressalva, é publicado sob a licença Creative Commons Atribição 4.0. 


\section{PATRIMÔNIO CULTURAL \\ IMATERIAL INDÍGENA: OS TAPUIA \\ PAIACU DO MUNICÍPIO DE APODI/RN}

Joelma Pinto de Sousa

\section{Introdução}

O presente capítulo trata-se de um estudo sobre o patrimônio cultural imaterial indígena dos Tapuia Paiacu do município de Apodi, município localizado na Mesorregião Oeste do estado do Rio Grande do Norte, Nordeste do Brasil. Na pesquisa em questão verificou-se como espaços fundamentais de observação o Centro Histórico-Cultural Tapuia Paiacu da Lagoa do Apodi e o Museu do Índio Luiza Cantofa, nos quais foi possível observar a presença de um acervo histórico de artefatos e informações que expressam as manifestações culturais e os modos de vida da comunidade Indígena Tapuia Paiacu. Para a composição de dados da pesquisa foram empregadas pesquisa bibliográficas e pesquisa de campo, com base na utilização de roteiros de observação e entrevista semiestruturada.

\section{Os Tapuia Paiacu de Apodi e as entidades de registro e exposição de sua cultura}

A população indígena no Brasil assume o número de aproximadamente 817 mil pessoas (IBGE, 2010), organizada em 270 etnias falantes de 180 línguas indígenas distintas. Para Melatti (1980) quando os europeus chegaram ao litoral brasileiro encontraram grupos indígenas de expressão linguísticas e culturais bem diversas, as quais foi possível classificar em três grandes troncos linguísticos: o Tupi, o Macro-Jê e o Aruaque. Muito 
embora, algumas línguas indígenas não se enquadravam nessas tipologias mais abrangentes (BANIWA, 2006, p. 43).

Em linhas gerais, os povos indígenas foram divididos em dois grandes grupos chamados de Tupi-Guarani e Tapuia (SANTOS JÚNIOR, 2008). De acordo com Fausto (1996), os tupis-guaranis ${ }^{23}$ se expandiram por uma boa parte da costa brasileira dominando a faixa litorânea do Norte até Cananéia, ao Sul do atual Estado de São Paulo (interior da região sul). Os Tapuia, por sua vez, estavam presentes nas regiões interioranas, desde a margem oeste do Rio São Francisco, na Bahia, até os sertões de vários estados nordestinos.

Na visão de Santos Júnior (2008) que se baseia nas pesquisas do professor Thomaz Pompeu Sobrinho, na Capitania do Rio Grande durante dos séculos XVI a XVIII, os Tapuia se dividiam em dois grupos: Os Tarairiu e os Cariri, os quais apresentavam algumas diferenças étnico-culturais.

Os Tarairiús possuíam características somáticas, representadas por uma elevada estatura, dolicocefalia, hipsicrania, possuindo, ademais, o tipo australóide. Culturalmente, encontravam-se no estágio do Paleolítico Superior, grau primário. Possuíam uma economia coletora. Como armas usavam a lança de arremesso, em que era colocada uma pedra pontiaguda. Também portavam o machado tosco. Os Cariris apresentavam características somáticas representadas por uma baixa estatura, braquicefalia, mesorrinia, o tipo mongolóide. Culturalmente, estavam na fase Neolítica média, praticando a agricultura, cuidando da cerâmica e da confecção de tecidos. Seguiam o direito matrilinear e avunculato. Praticavam a navegação, com canoas monóxilas. Como armas, usavam arco e flecha, além de zarabatana (MEDEIROS FILHO, 1984, p. 25, apud SANTOS JÚNIOR, 2008, p. 12).

23 Além dessa localização geográfica diversificada dos Tupi e dos Guarani, pronunciamos simultaneamente Tupi-Guarani, dada a homogeneidade cultural e linguística (SANTOS JÚNIOR, 2008). 
Reportando-se especialmente para o município de Apodi ${ }^{24}$. O mesmo é conhecido como à terra dos índios Tapuia Paiacu da Lagoa do Apodi, originários do grupo Tarairiú. Segundo relatos de Guerra (1982), Pacheco e Baumann (2006), eles foram os primeiros que povoaram o território apodiense e viviam em nossas terras em entendimento com o meio ambiente. Isto, antes da chegada dos invasores homens brancos que vieram com o intuito de explorar as terras que pertenciam aos índios nativos dessa região. Com o domínio do homem branco os índios nativos passaram a ser explorados e expulsos de sua terra natal.

Apodi sempre foi uma terra muito rica em água, especialmente a região do vale, essa riqueza não iria estabelecer uma exceção, na fase em que se processava a colonização no Brasil. Com isso, aqui chegavam os primeiros migrantes, atraídos pela grande quantidade d'água existente na lagoa, nos rios e no vale (PACHECO; BAUMANN, 2006).

Os Tapuia Paiacu viviam no Vale do Apodi, nas margens da lagoa, nos rios e na chapada, onde exerciam agricultura rudimentar, pesca e caça. É possível que praticassem o artesanato de cerâmica de barro e outras atividades similares, pois, tinham, assim como outras tribos, a sua cultura estética particular (PACHECO; BAUMANN, 2006). Segundo os autores, foram identificados registros desses povos nativos no sítio arqueológico conhecido como Lajedo de Soledade, no qual, se encontram vários painéis com exposições rupestres (pinturas e gravuras), correspondente a imagens de animais, elementos da natureza e formas geométricas. Os índios Tapuia Paiacu, destacam-se pela diversidade cultural e pela sua influência na formação histórico-cultural de Apodi. No quadro 1 a seguir, está especificado pontos de diversidade cultural dos Tapuia Paiacu segundo o entendimento dos autores Pacheco e Baumann (2006) e Santo Júnior (2008).

24 Com efeito, percebe-se a forte ligação existente nome de Apodi e sua origem indígena. A etimologia da palavra refere-se a coisa firme, altura unida, um planalto, uma chapada. Outra versão explica que o topônimo Apodi é uma derivação da palavra POTY ou PODY, que quer dizer camarão na língua dos índios Paiacu (PACHECO; BAUMANN, 2006). 
Quadro 1 - Diversidade cultural dos Tapuia Paiacu

\section{DIVIERSIIDADE CULHURATL DOS THAPUIA PATACU}

\section{Linguagem}

Costumes

Crenças

Alimentação

Saúde

Habitação

Vestimentas
A língua dos Tapuia era bem diferente e até para seus aliados era difícil compreender — "língua travada".

Queimar os ossos de animais e espinhas de peixes, que para eles, significava atrair felicidade. Os índios caçadores mais novos presenteavam os mais velhos da aldeia com caças e pescarias.

Crença religiosa "animista" atribui características pessoais e humanas as forças da natureza, como: o sol, a lua e o trovão. Ademais, eles crêem que certos animais como: aves, serpentes, e alguns mamíferos (morcegos) tinham poderes; praticavam sacrifícios de animais e até de humanos.

Mel de abelha, peixes, caça e de alguns alimentos da roça (mandioca, jerimuns, milho e frutas).

Se um índio adoecia, os demais faziam defumações com tabaco, inserindo folhas de certos vegetais na garganta do doente, para estimular vômitos, aspirações bucais e com o uso de plantas medicinais.

Os índios habitavam em ocas feitas de madeira com coberturas de palhas ou galhos de plantas.

Cobriam as partes intimas com peças confeccionadas de materiais rústicos, retirados da natureza. Já as 'índias escondiam suas partes intimas com um avental feito de folhas. Calçavam sandália (feitas com casca de arvore chamada curaguá).

Fonte: Autoria própria (2019).

Como espaço de expressão da identidade e a memória indígena tem-se o Centro Histórico-Cultural Tapuias Paiacus da Lagoa do Apodi (CHCTPLA). O mesmo possui um conjunto expressivo de peças líticas de populações que povoaram a região do município. Ou seja, o local é uma boa opção para os estudiosos que buscam mais aprofundamento quanto aos conhecimentos acerca do patrimônio material/imaterial e histórico que expressa fatores da formação cultural dos povos que se constituiu na região do médio e alto oeste potiguar, semiárido do Nordeste. 
A partir da estruturação dessa entidade é fundado em 07 de fevereiro de 2013 o Museu "Luíza Cantofa", instituição que homenageia uma mulher indígena que se destacou e liderou a tribo dos Tapuias Paiacus, assassinada de forma trágica na cidade de Portalegre/RN, em 1825. Segundo Freitas (2018), a instituição é o primeiro museu indígena do estado do Rio Grande do Norte que ganhou reconhecimento oficial. Sendo assim, é considerado como um patrimônio histórico-cultural com bens de natureza material e imaterial dos índios Tapuias Paiacus.

O CHCTPLA e o museu do Índio Luiza Cantofa, tem como presidente e fundadora Lúcia Maria Tavares conhecida por Lúcia Tapuia Paiacu. Nascida em 1961, no município de Apodi/RN, Lúcia é Filha de um agricultor e ex-combatente, seu Sebastião Clementino Tavares e de uma Lavadeira, Dona Maria das Neves da Conceição (FREITAS, 2018). A fundadora é bastante atuante nos movimentos indigenistas e participa de eventos em defesa dos direitos indígenas, como: conferências, fóruns, entre outros. Atualmente, participa da "Feira de Artesanato Divinas Mãos ${ }^{25 "}$ em Apodi, onde é possível prestigiar e valorizar a arte dos artesãos locais. A referida feira possibilita o reconhecimento da cultura e história indígena dos Tapuias Paiacus da ribeira do Apodi.

Para a formação do acervo, a princípio foi feito um levantamento histórico-cultural do lugar, no qual, foi possível identificar a presença dos indígenas Tapuias Paiacus, a partir dessas informações, Lúcia investigou afundo sua origem, por meio de visitas nas comunidades, buscando conhecer as famílias e juntar arquivos vivos como peças e documentos que representam a história e a cultura desse povo.

Conforme membro do CHCTPLA (2019), as peças do acervo são adquiridas de todos os lugares do município de Apodi e de regiões próximas. Sendo também obtidas através de famílias que tinham peças guardadas dos seus avós, peças essas de forma líticas, como: machadinhas, cachimbos,

25 Ocorre em frente à Igreja Matriz, evento esse que é promovido pela Prefeitura de Apodi, por meio da Secretaria Municipal da Mulher e da Igualdade Racial. Realizada uma vez por mês. Ao todo são 30 barracas disponíveis para 62 artesãos, com as mais variadas peças artesanais. Disponível em: http://www.apodiario.com. br/2019/05/feira-de-artesanato-divinas-maos-e.html. Acesso em: 28 jun. 2019. 
agulhão de osso, gargantilha de pedra, lascas de pedras, pilão de pedra, entre outras. Estas peças estão expostas no Centro Histórico para quem desejar conhecê-las. No quadro a seguir, dispomos algumas informações sobre artefatos e acervos de peças artesanais no CHCTPLA, respectivamente.

Quadro 2 - Informações sobre os artefatos do Centro Histórico.

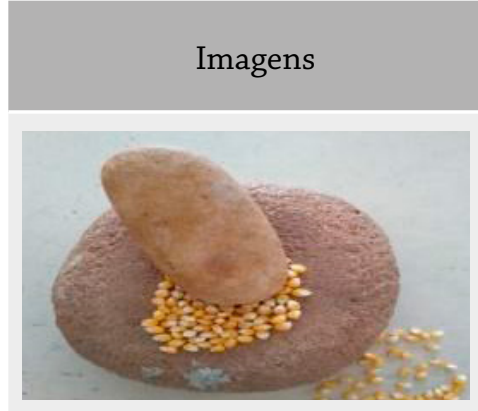

$\begin{array}{lll}\text { Descrições } & \begin{array}{l}\text { Recebida e } \\ \text { Encontrada }\end{array} & \begin{array}{l}\text { Local onde foi } \\ \text { encontrada }\end{array}\end{array}$

Pilão e Almofa- 13/02/2019 Rio Mari em riz de padra Recebida Apodi

Fonte: Facebook Lucia Maria Tavares (2019).

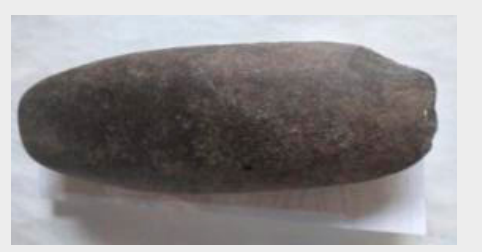

$\begin{array}{lll}\text { Machadinha } & \text { 22/12/2018 Apodi/RN } \\ \text { lítica } & \text { Recebida por } & \\ & \text { Welitton Souza }\end{array}$

Fonte: Facebook Lucia Maria Tavares (2018).
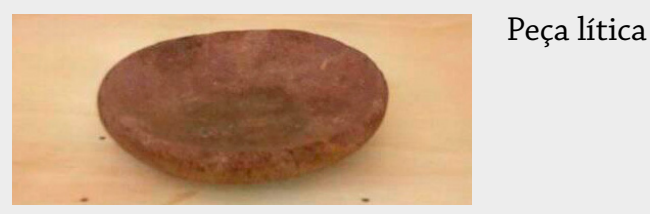

$18 / 10 / 18$

Sitio Bico Tor-

Recebida to, Apodi/RN

Fonte: Facebook Lucia Maria Tavares (2018).

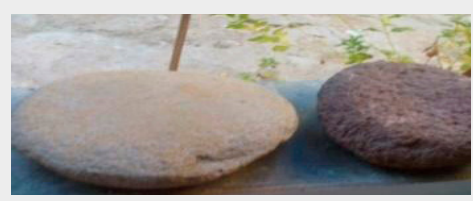

Peças Almo-

11/06/18

Região da Vár-

fariz

Encontradas

zea em Apodi

Fonte: Facebook Lucia Maria Tavares (2018).

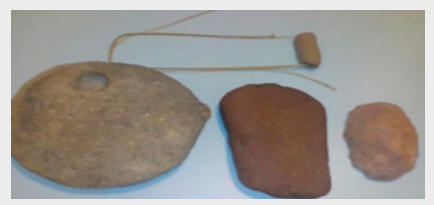

Machadinha

Encontradas

Viçosa/RN

muito antiga e pela pesquisa-

um pingente dora.

Fonte: Freitas (2018, p.132). 


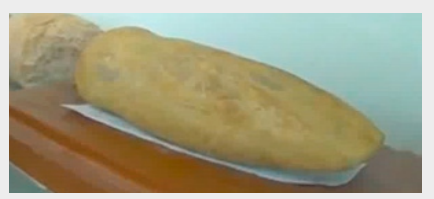

Machadinha Encontrada

Bairro Baixa

do CAIC em

Apodi/RN

Fonte: Resenhas do RN Apodi $1^{\circ}$ parte.

\section{ACERVOS DO CHCTPLA- PEÇAS ARTESANAL}
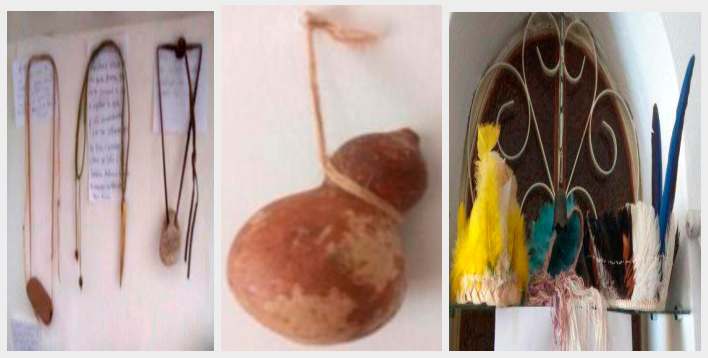

Colar com pingentes de ossos, dentes, pedras, usava no pescoço.

Cabaça feita do fruto da cuieira, usada para armazenamento de água.

Cocares são confeccionados de penas e plumas de aves, utilizados nos ornamentos para o corpo.

Fonte: Arquivo do CHCTPLA.

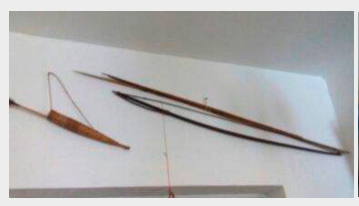

Fonte: Arquivo do CHCTPLA.

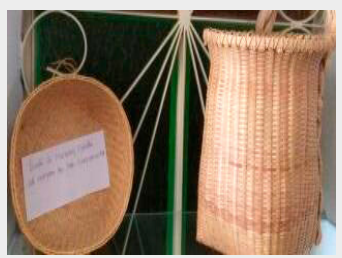

Fonte: Arquivo do CHCTPLA.

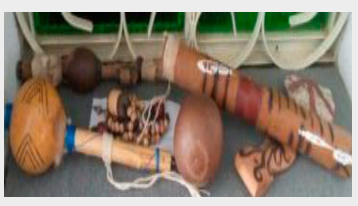

Arcos e flechas - instrumentos de trabalho, usada para caçar e pescar.

Instrumentos musicais como maracá, instrumento de percussão Pau-de-chuva e apito. São usados para diversos rituais.

Cestas de palha de carnaúba, usadas para transportar alimentos e objetos.

Cerâmicas feitas de argila como pote, vasilha, cabaça e entre outros. São utilizados no armazenamento de água.

Fonte: Autoria própria (2016).

De acordo com membro do CHCTPLA (2019), atualmente, o Museu conta com cerca de aproximadamente 200 peças, muitas delas foram encontradas pela pesquisadora Lúcia e outras foram doadas por pessoas de várias localidades. O mesmo é aberto ao público e seus principais visitantes são 
estudantes, pesquisadores e pessoas que se interessam em conhecer a história indígena de Apodi. Porém, o Museu não fica aberto diariamente, para visitá-lo é preciso ligar com antecedência para marcar o dia e horário de visita. Para visitação, o Museu cobra uma taxa simbólica para manter os custos e preservação do local.

Podemos identificar que o CHCTPLA realiza algumas ações educativas, culturais e ambientais, dentre elas, a "oficina de Combate à Violência Contra a Mulher Indígena com o povo Tapuias Paiacus da Lagoa do Apodi", a "oficina pintura e identidade indígena", reuniões com coordenador da FUNAI, participação no desfile 7 de setembro étnicos do Apodi, arborização entorno da lagoa, exposição de peças indígenas artesanais na Feira de Artesanato “Divinas Mãos" em Apodi, entre outras. Percebe-se ainda que, o CHCTPLA ativo, proporcionou uma valorização e reconhecimento da história e do patrimônio cultural imaterial indígena dos Tapuias Paiacus por parte da população local. Um exemplo disso é o livro de literatura infantil intitulado "Apodi dos índios Tapuias Paiacus" da autora mirim Anne Sofia Viana que introduz a História indígena de Apodi.

Foi a partir da fundação do CHCTPLA, pelos Tapuias Paiacu de Apodi, que houve o fortalecimento do movimento pelos direitos das populações indígenas e também o fortalecimento do processo de autoafirmação das famílias indígenas.

O processo de autoafirmação é permanente, visto que a qualquer momento podem surgir novas pessoas que queiram se autoafirmar. A coleta dos depoimentos é feita individualmente, às vezes na casa da pessoa que decide confirmar sua autoafirmação, como também na própria sede do CHCTPLA (FREITAS, 2018, p. 134).

"Cada autoafirmação ela grava o depoimento em vídeo e posta em Rede Social para não perder o registro CHCTPLA" (FREITAS, 2018, p. 133-134). A mesma, é bastante atuante nas redes sociais (Facebook e Instagram). No entanto usa mais o Facebook pessoal (perfil Lúcia Maria Tavares) e o do Centro Histórico-Cultural Tapuias Paiacus de Apodi, no qual faz postagens de vídeos gravados e registros fotográficos das auto afirmações daqueles que se autodeclaram indígenas Tapuia Paiacu. 
Para Freitas (2018), o projeto que possibilitou a inserção das famílias Tapuia Paiacu, contribuiu para a consolidação das lutas, conquistas, e fortalecimento dos indígenas em ocupar um espaço diante a sociedade, assim como, na busca por seus direitos, tendo como pioneira na idealização do projeto, Lúcia Tapuia Paiacu. Foram realizadas diversas expedições, podendo contar com seis pesquisas de campo realizadas em vários lugares, sendo de grande importância para o processo de autoafirmação étnica e de atuação da FUNAI junto a esse povo.

O processo de autoafirmação que proporcionou o contato de um grupo de Tapuia Paiacu do Apodi com membros da APOINME no Rio Grande do Norte desde o ano de 2013, através de Lúcia Tapuia Paiacu que também é presidenta do Centro Histórico Cultural Tapuia Paiacu da Lagoa do Apodi (CHCTPLA). Este contato garantiu que tanto a FUNAI como a APOINME tomassem conhecimento sobre a existência desse grupo em Apodi, além dos já conhecidos. Daí em diante, os índios desse município se engajaram aos demais do Rio Grande do Norte, realizando mobilizações através de assembleias, seminários e conferências (FREITAS, 2018, p.76).

Ainda de acordo com o membro do CHCTPLA (2019), existem cerca de 65 famílias auto afirmadas indígenas encontradas no Sítio Boca da Mata, Bico Torto, Córrego, Bela Vista, Assentamento Aurora da Serra, dentre outros, que em sua maioria são agricultores e atuantes da atividade de pesca e caça. Uma das grandes conquistas das mulheres indígenas e marco histórico para as mesmas foi a $1^{\mathrm{a}}$ Marcha das Mulheres Indígenas, com a temática "Território: nosso corpo, nosso espírito", que ocorreu entre os dias 9 e 14 de agosto de 2019, em Brasília.

A Marcha é uma conquista de muitas mulheres, pertencentes a diversos povos que lutam diariamente a fim de dar visibilidade e voz para as suas causas próprias. A Marcha é fruto de uma extensa luta por reconhecimento e espaço dentro dos movimentos indígenas e também perante a sociedade brasileira (CIMI - Conselho Indígena Missionário, 2019).

No dia 07 de outubro de 2019, Lúcia conquistou uma grande vitória: 
Recebo a notícia da vitória de uma das minhas lutas mais importantes para a confirmação da existência da etnia Paiacu, da qual sou pertencente e ascendente. Recebo a notícia de que o juiz da Vara Cível de Apodi proferiu a sentença em meu favor. Agora, oficialmente podem me chamar de (LÚCIA PAIACU TABAJARA). Confirma-se oficialmente a existência do povo Paiacu do APODI (FACEBOOK LUCIA MARIA TAVARES, 2019).

\section{Considerações Finais}

Portanto, este cenário mostra mais uma conquista da luta e persistência dessa mulher indígena em busca do reconhecimento da cultura e da existência dos povos indígenas Tapuias Paiacus no Município de Apodi/RN. Evidenciamos nesta pesquisa, que o CHCTPLA é um espaço de suma importância para a população apodiense, pois, guarda registros e relíquias da memória viva dos primeiros habitantes do município de Apodi, contribuindo para a valorização da cultura e reconhecimento da origem indenitária. Nesse sentido, é relevante o desenvolvimento de ações similares, com a finalidade de informar à sociedade sobre a riqueza da produção material e imaterial desses grupos, manifesta nos seus modos de ver, modos de conhecer e modos de fazer. 


\section{REFERÊNCIAS}

BANIWA. G. S. L. 0 Índio Brasileiro: o que você precisa saber sobre os povos indígenas no Brasil de hoje. Brasília: Ministério da Educação, 2006. (Coleção Educação para todos, 12).

FAUSTO, B. História do Brasil: História do Brasil cobre um período de mais de quinhentos anos, desde as raízes da colonização portuguesa até nossos dias. São Paulo: Edusp, 1996.

FREITAS, M. M. Relatos sobre o massacre de $\mathbf{7 0}$ índios na serra de Portalegre/RN: argumentação em discursos de liderança indígena e alunos do ensino fundamental. 2018. 297 f. Dissertação (Mestrado) Universidade do Estado do Rio Grande do Norte, Pau dos Ferros, 2018. GUERRA, V. B. Apodi no passado e no presente. 2. ed. 1982. (Coleção Mossoroense. v. CII).

IBGE-INSTITUTO BRASILEIRO DE GEOGRAFIA E ESTATÍSTICA.

População. Rio de Janeiro: IBGE, 2017. Disponível em: https://bit. ly/2Rmz7ri. Acesso em: 20 jan. 2019.

IEPÉ-Patrimônio Cultural Imaterial e Povos Indígenas. [S.l.:s.n.]2006.

MELATTI, J. C. Índios do Brasil. Hucitec, 1980.

PACHECO, C. B.; BAUMANN, J. C. Apodi: um olhar em sua diversidade. Natal: Cida Ramos, 2006. p. 86-106. 
PEREIRA, E. S. Patrimônio Cultural Imaterial: uma reflexão sobre o registro do bem cultural como forma de preservação. São Paulo: USP, 2012.

PUNTONI, P. A Arte da guerra no Brasil: tecnologia e estratégia militar na expansão da fronteira da América Portuguesa, 1550-1700. Novos Estudos, n. 53, p. 189-204, mar. 1999.

RIBEIRO, D. O Povo brasileiro: a formação e o sentido do Brasil. 2. ed. São Paulo: Companhia das Letras, 1995.

SANTOS JÚNIOR, V. Os Índios Tapuias do Rio Grande do Norte: antepassados esquecidos. Mossoró, 2008. p. 32-37. 